\title{
UN NIETZSCHE EXTRAÑO: INTERSECCIONES ENTRE EL PENSAMIENTO NIETZSCHEANO Y LA TEORÍA QUEER
}

\section{A QUEER NIETZSCHE: INTERSECTIONS BETWEEN NIETZSCHEAN THOUGHT AND QUEER THEORY}

\author{
Jonathan Piedra Alegría \\ Universidad Nacional, Costa Rica \\ jon21700@hotmail.com
}

Recibido: 12 de enero de 2018 • Aceptado: 2 de febrero de 2018 Publicado: 28 de mayo de 2018

\section{Resumen}

En este documento se se reflexiona sobre las posibles influencias de Nietzsche en la teoría queer. Para esto, se analizan las intersecciones y puntos en común entre el perspectivismo nietzscheano, así como su crítica a la metafísica de la sustancia y la teoría de los actos performativos de Butler.

Palabras clave: Nietzsche, Butler, teoría queer, performatividad, perspectivismo.

\begin{abstract}
This paper analyzes the possible influences of Nietzsche on Queer Theory. For this purpose, we analyze the intersections and points in common between nietzschean perspectivism, as well as his critique of the metaphysics of substance and the theory of performative acts of Butler.
\end{abstract}

Key words: Nietzsche, Butler, queer theory, performativity, perspectivism.

\section{Introducción}

\footnotetext{
1 término queer es una palabra anglosajona que cuando se usa como adjetivo significa literalmente "extraño" o "raro". A partir de los primeros años del siglo XX, se empezó a utilizar queer de manera despectiva e insultante hacia la población homosexual y lesbiana, principalmente. Siendo
} 
así, esta palabra (en sus distintas acepciones) era muestra de la desvaloración de un grupo predominante de la sociedad hacia quienes no cumplían los roles sociales establecidos por la heteronormatividad. En contexto surgió la teoría queer (TQ), ya que esta pretende resignificar este aspecto peyorativo, para volverlo algo digno de estudio e investigación, haciendo de lo raro una categoría de análisis. En general, uno de los principales temas de la TQ es la crítica y desconstrucción de las concepciones usualmente aceptadas de masculinidad y feminidad, todas ellas agrupadas en el binomio sexo-género, así como la relación de esto con el deseo.

Este ensayo pretende mostrar que algunos de los fundamentos filosóficos más importantes en la obra de Judith Butler (una teórica fundamental para la TQ) pueden rastrearse hasta un autor que tuvo un profundo impacto en el desarrollo de la filosofía contemporánea: Friedrich Nietzsche. Es así como en este escrito se realizará una lectura extraña de Nietzsche, específicamente en dos aspectos fundamentales en el desarrollo de la TQ: la noción de subjetividad y la idea del perspectivismo. Esto, debido a que estas dos categorías nietzscheanas presentan interesantes puntos de encuentro con la TQ, sobre todo en la matriz profundamente antiesencialista de Nietzsche y su tendencia a analizar a los seres humanos desde una "lucha de fuerzas" corporales, sociales e individuales.

\section{El cuerpo en la filosofía nietzscheana}

Una de sus reflexiones más importantes está relacionada con la subjetividad propiamente moderna con la forma en que Nietzsche considera que el cuerpo demuestra una anulación del proceso de centralización llevado por el "yo". En Über Wahrheit und Lüge im aussermoralischen Sinne plantea lo que podría denominarse su teoría genealógica del lenguaje. En este escrito, nos muestra cómo el lenguaje surge de un proceso de degradación ontológica que se da en tres etapas de metaforización. En un primer momento (I), la realidad se nos aparece en su sensibilidad más elemental, como un conjunto de impresiones y estímulos nerviosos. Frente a esto (y debido a nuestra "voluntad de verdad") degradamos a (II) esta impresión en una metáfora que representa simplemente una imagen. Esta imagen sufre otro proceso y se convierte en sonido, para que finalmente (III) estos se transformen en 
palabras, o más propiamente, en lenguaje. No obstante, la existencia misma del lenguaje supone una igualación de lo desigual, al prescindir del elemento individual de estas impresiones nerviosas, por medio de la generalidad conceptual del lenguaje. Esto provoca no solo que se oculte la realidad, sino que se genere una inversión ontológica, en donde damos por existentes conceptos abstractos y generales como el bien, el mal, el alma o el yo.

El yo, en algún momento fue una metáfora que mostraban una relación entre nosotros y la cosas. El yo (sujeto) representaba una unidad que nos diferenciaba de los no-yos (objetos); pero para esto debía basarse en un principio de continuidad y sustancialidad. Es así como (y siguiendo el proceso de degradación ontológica) tuvo que perder su elemento metafórico y volverse conceptual. En este sentido, no refleja una unidad subyacente o metafísica, ni una característica psicológica sustancial de los seres humanos, lo único que muestra son las reglas lógico-formales propias del lenguaje ${ }^{1}$.

Pero "Nietzsche, who thinks of life as something extralogical, through his style or text strives to exceed the limits of logical discourse, in order to enable the text, a meaning that is always constituted in a said, to be the saying of life, ... the body... [Nietzsche, que piensa en la vida como algo extra lógico, a través de su estilo o de su texto, se esfuerza por exceder los límites del discurso lógico, para permitir que el texto, un sentido que siempre es constituido en un decir, sea el decir de la vida ... el cuerpo...]" (Blondel, 1991, p. 22).

No obstante, si siempre se ha creído que el yo es el centro de nuestras creencias, el foco de nuestra identidad, el locus de nuestras interpretaciones y según Nietzsche no es así, la pregunta que surgiría es: ¿quién interpreta? (Wer legt aus?). No es un sujeto, ni un yo metafísico o psicológico. Entonces, ¿quién lo hace? Pues nuestro cuerpo lo hace y lo hace porque es la totalidad de las interpretaciones de la cual, el yo es solo una parte, y una parte menor, según Nietzsche. La verdad del yo es el cuerpo. Ya que “...beneath the networks of concept and grammar, the metaphor follows what Nietzsche call the Leitfaden des Leibes (the evidence of the body), life's secret coherence [... bajo las redes del concepto y de la gramática, la metáfora sigue lo que Nietzsche llama el Leitfaden des Leibes (la evidencia del cuerpo), la coherencia secreta

1 La gramática según Nietzsche. 
de la vida]" (Blondel, 1991, p. 28). No obstante, es este concepto, lo que tomamos como verdadero o como lo real.

Debido a este proceso, tomamos por cierto al sujeto, al yo como si tuviera una realidad ontológica, y no lo consideramos solamente como un modo de interpretar la realidad. El yo no es una entidad real, como tampoco lo es el sujeto. El yo es una manera discursiva (teórica) de interpretar la sensación de unidad orgánica del cuerpo. Opuestamente a lo que se opina, el cuerpo es el que, de alguna manera, proyecta la existencia de esta unidad simbólica, "El «yo» (¡que no es idéntico a la dirección unitaria de nuestro ser!) es tan sólo una síntesis conceptual” (Nietzsche, 2006, p. 87). Este punto resulta muy importante, ya que muestra que el yo no es origen de todo el conocimiento como usualmente se ha considerado, sino que el centro es el cuerpo vivido (Leib).

A partir de estas ideas, Nietzsche va dándole forma a su teoría del cuerpo como una organización de múltiples interpretaciones vitales y centros de fuerzas, que se expresan en una pluralidad de impulsos. El cuerpo sería, en este caso, la realidad primera, mientras que el sujeto es solo una creación del cuerpo. Por lo que la conciencia, el sujeto, el alma o el yo son solamente unas ficciones que sirven como síntesis conceptuales, porque, en definitiva, la unidad e identidad de los individuos se basan en la constitución y en la organización del cuerpo y no en la historia psicológica ${ }^{2}$ del yo.

Por tanto, cualquier especulación que implique algún tipo de centralización psicológica o metafísica mostraría ser errónea en vista de nuestra pluralidad constitutiva. Esto quiere decir que una comprensión adecuada de la corporalidad implicaría tomarla desde su multiplicidad no solo anatómica, sino, además, constitutivo-simbólica. Mientras que en la historia de la filosofía se busca un principio unificador que sea homogéneo y claro, Nietzsche insiste más bien en la multiplicidad irreductible de incluso un cuerpo individual, de forma que "el alma" o "el yo" resultan inadecuados para explicar o dar cuenta de la complejidad del ser humano. La clave radica en que cada individuo es en sí mismo una colectividad (de instintos, de fuerzas, de "almas").

2 "Historia psicológica del concepto "sujeto". El cuerpo, la cosa, la totalidad construida por el ojo suscita la distinción entre un hacer y un agente, el agente, la causa del obrar, concebido con una sutilidad continuamente acrecentada, ha dejado finalmente un resto: el "sujeto". (Nietzsche, 2008b, p. 158) 
Entre la pluralidad del mundo (que es un puro caos -el devenir-) y la simplificación de este mismo (por el intelecto -conceptos, teoría-), se encuentra el cuerpo. Es decir, el cuerpo es el intermediario entre estos dos aspectos, creando en él mismo una comprensión no reduccionista (contrariamente al yo) del mundo. Esto provoca que la idea clásica mecanicista del cuerpo debe ser desechada. No en vano podemos observar cómo el pensamiento nietzscheano juega y vacila con la ambigüedad del cuerpo, que no es ni únicamente fisiológica-biológica, ni estrictamente simbólica. El cuerpo no se resume a la biología, sino que implica la multiplicidad de las experiencias sociales, así como la experiencia individual al mismo tiempo. Por esto, el individuo no es propiamente una individualidad, sino una colectividad de fuerzas que operan en la organización que llamamos cuerpo.

Por lo cual, al igual que con el lenguaje ocurre un proceso de degradación ontológica de realidad, la corporalidad se ve cubierta por el "lenguaje de la conciencia”. Nietzsche no se propone una descripción materialista o reducir la conciencia al cuerpo, sino una interpretación distinta, un desvarío de la metafísica de la sustancia y del dualismo tradicional. El yo es solo un instrumento del cuerpo, que no queda al margen de esta lucha, sino que es parte de esta. Es así como existe una relación metafórica (que no es inequívoca) entre la subjetividad y el cuerpo, ya que la subjetividad no puede separase ni distinguirse del lenguaje.

La distinción entre uno y otro es meramente formal, ya que no existe un solo cuerpo o un solo yo, como ya hemos mencionado. Lo que Nietzsche propone con estas posiciones es evidenciar la amplitud de las dimensiones de la corporeidad por medio de un discurso simbólico que muestra la capacidad creadora de la voluntad de poder, en clara oposición a muchas posiciones reduccionistas (metafísicas, psicológicas e inclusive biologicistas) que parten de un lenguaje descriptivo que quiere simplificar el ser humano en mónadas o átomos unitarios. La corporalidad (al igual que la metáfora) representa el movimiento constante de la voluntad de poder, de la creación de perspectivas llenas de sentido. Es así como la experiencia de la corporalidad adquiere sentido como una escenografía donde gravita lo social, al mismo tiempo que lo individual. 


\section{Un ojo sin dirección alguna}

Según nuestra interpretación, para Nietzsche las perspectivas deben entenderse desde lo que podríamos llamar matrices de poder. Estas matrices serían dinámicas individuales-sociales que reflejan ciertas opciones vitales-existenciales que representan condiciones de conservación y crecimiento (del poder). Es decir, la creación de perspectivas es un método de subsistencia existencial que crea mundos posibles dentro de la pluralidad de circunstancias y escenarios de la existencia humana. En este sentido, cada perspectiva se muestra como "verdadera", en un afán de perpetuarse y acrecentar su poder. En ocasiones estas matrices de poder pueden interactuar con otras matrices, y producen una interpretación nueva. En otros momentos, se imponen sobre las demás, de forma tal que se auto conserve una interpretación en detrimento de otra. No hay ninguna perspectiva verdadera en sí, a pesar de que se muestren como tales, ya que esto sería un contrasentido. Esto aun cuando cada perspectiva se muestre como la única verdadera, debido a la naturaleza impositiva del poder y no a las características particulares de la perspectiva en sí. Ninguna interpretación capta la esencia de la realidad, en vista de que la creencia en la existencia de esencias es ya un mirar con perspectiva. Todo se interpreta dentro de las matrices de poder. Siempre hay que retrotraerse al ser humano, que presenta el límite epistemológico supremo y, a partir de ahí, es desde donde se crean las valoraciones. Los seres humanos vendríamos a ser intersecciones de diversas perspectivas que, a su vez, estarían formuladas por una mixtura de creencias, valores de todo tipo, así como de corrientes cognoscitivas específicas. De manera tal que todas las perspectivas representan intereses, es decir, son interesadas puesto que incorporan diferentes valoraciones. Por lo tanto, no hay hechos ni perspectivas objetivas (Nietzsche, 2003b, párr.12]).

El autor alemán muestra una desvaloración por todo aquello que pretende mostrarse como una verdad objetiva o un conocimiento puro. La verdad pura es igual de infame que la razón pura o el conocimiento en sí. Algo así sería tan absurdo como un ojo que no tiene dirección alguna. Las interpretaciones son valiosas por su carácter subjetivo, ya que muestran "fuerzas activas" que les dan valor a las cosas. Es por esto por lo que los sentidos existenciales o las interpretaciones en general no pueden reducirse 
a única unidad (lo objetivo, lo en-sí o lo puro), ya que: "el hombre es una pluralidad de 'voluntades de poder': cada una con una pluralidad de medios de expresión y de formas" (Nietzsche 2006, p. 58). Es así como esta pluralidad de "voluntades de poder" nos lleva a "relaciones de valor" que tienen, como "instancias valorativas", las "fuerzas activas e interpretativas" propias de las condiciones vitales individuales, junto a las complejas relaciones sociales que representan las matrices de poder (Nietzsche, 2006, 3]; IV, 242-3, 9 [38]). Es precisamente esto, lo que hace que lo objetivo sea algo peligroso, puesto que limita nuestra capacidad de conocer. "Un solo ojo" nunca podría brindar un conocimiento complejo y amplio de la realidad. Lo "objetivo" se vuelve valioso cuando hay una multiplicidad de interpretaciones que lo complementan y lo muestran en su "verdad" particular.

De igual manera que una persona es incapaz de verse a sí misma de la forma en como la miran las demás personas, nadie puede ver la realidad como totalidad, sino siempre esta se hace desde un sesgo. Mientras más interpretaciones tengamos de lo "objetivo", más nos aproximaremos "a lo verdadero". Es claro que Nietzsche se refiere, con esto, a que esa verdad (o lo verdadero) es únicamente una perspectiva inteligible para los demás individuos y, en cierta medida, generalizable en tanto es una afirmación propia de los pueblos, culturas o grupos sociales. Ello, sin duda, implica que hacen falta muchos ojos para tener un conocimiento cada vez más completo sobre algo.

Una consecuencia de este planteamiento es que el "sujeto" solo puede darse o existir por medio de la interacción de otras perspectivas. Es decir, no existe un sujeto preconstituido o prediscursivo (este aspecto será tomado con gran entusiasmo por la TQ) que concurra previo a una instancia de valoración o a una matriz de poder que lo considera valioso. No existe un "sujeto abstracto", como tampoco existe una "realidad objetiva". En este momento es claro que Nietzsche defiende una postura antiesencialista de la subjetividad, la cual vendrá a tener profundas implicaciones en la TQ.

Nietzsche consideraba que tenemos la mala costumbre de referirnos a las cosas como si estas tuvieran un sentido independiente de nosotros o nosotras. Por lo general, lo único que vemos es lo estático, cuando lo que en el fondo se da es únicamente el movimiento. Esta idea puede servir como analogía para el punto que queremos desarrollar. Si notamos un cambio de algo, es porque, efectivamente, tenemos un punto de referencia sobre el cual 
nos basamos. Esta referencia (interpretación) en muchas ocasiones puede llegar a convertirse en la "única referencia" y, por lo tanto, esta referencia es la que nos brinda la verdad o falsedad de algo; lo que impide que podamos hablar de algo en sí, o de algún hecho en sí. En los Fragmentos póstumos de final de 1886- primavera de 1887, Nietzsche nos mencionaba esto con claridad: “"Todo es subjetivo», decís vosotros: pero ya eso es interpretación, el «sujeto» no es algo dado sino algo inventado y añadido, algo puesto por detrás. - ¿Es en última instancia necesario poner aún al intérprete detrás de la interpretación? Ya eso es invención, hipótesis. En la medida en que la palabra «conocimiento» tiene sentido, el mundo es cognoscible: pero es interpretable de otro modo, no tiene un sentido detrás de sí, sino innumerables sentidos, «perspectivismo»." (p. 60). En esta cita queda muy claro que hasta el mismo "sujeto" es parte de una interpretación. Lo anterior implica, no solo un abandono al esencialismo metafísico o al sustrato ontológico del yo, sino, además, una nueva forma de interpretar la subjetividad.

\subsection{El mundo en el espejo}

Así que el mismo sujeto (moderno, psicológico, metafísico) es ya una construcción. Es decir, no existe un sujeto cognoscitivo previo antes del aspecto sociocultural. Este sujeto se da en un proceso de aprendizaje social y en una lucha de fuerzas, de valores contrapuestos, teorías científicas o de perspectivas morales de la realidad y del ser humano. Dado que todo es interpretación, lo que asumimos como subjetivo ${ }^{3}$, no es más que un largo proceso de interpretación, en donde han aparecido incontables sentidos-existenciales e innumerables perspectivas vitales que luchan por aumentar su poder o por acrecentar el dominio. Esto impide en sentido práctico (más no formal o conceptual) a una unidad que las englobe a todas ellas, aun cuando, por diversos motivos, creamos que esas interpretaciones son verdaderas.

Según Nietzsche, hablamos como si hubieran "cosas que son”, pero el único modo en como las cosas tienen sentido es si están dentro de la "óptica humana”. Pensar algo fuera de ella o que existe aún antes de esta no solo es algo absurdo, sino del todo incomprensible. Cada vez que buscamos lo

3 Aquí utilizamos esta palabra en sentido kantiano, es decir, como producto del sujeto. 
objetivo, solo encontramos las perspectivas subjetivas. Cuando queremos acercarnos al origen incólume de algo, siempre nos topamos con matrices de poder. Es decir, las cosas han llegado a ser, las esencias se han vueltos tales y el sujeto se ha convertido en un sustrato.

Es claro, entonces, que sí todo se devuelve al ser humano y sus interpretaciones, las matrices de poder hacen referencias a procesos históricos sociales que son el origen de todas nuestras valoraciones o interpretaciones, las cuales, en una lucha con los instintos y los propios deseos personales ("fuerzas corporales activas"), producen las verdades morales, religiosas o científicas, por ejemplo, que, dependiendo de las condiciones, llegan a imponerse o no.

El "sujeto" no solo vendría a ser una ficción regulativa, sino que, además, mostraría su cara plenamente social, lo que nos llevaría a un punto de importancia para el posterior desarrollo de la TQ. Para Nietzsche no es un subjectum, sino una voluntad de poder (en el sentido que hemos venido señalado) la que interpreta o dice (haciendo referencia al lenguaje); para esto Nietzsche realiza una investigación genealógica sobre el tipo de matriz o voluntad de poder que se manifiesta en el discurso dominante o en la interpretación "válida".

\section{III. ¿Por qué hablamos de sexo cuando queremos decir género?}

Esta línea es retomada por la TQ, particularmente Judith Butler en su obra El género en disputa. Un dato interesante que la autora mencionó posteriormente a su publicación es que en este texto utilizó una metodología que ella denominó como "genealogía crítica", con lo cual se muestra deudora del método iniciado por Nietzsche. Este texto, básicamente, tiene como objetivo una revaloración y una resignificación del feminismo de ese momento, el cual, según Butler, no se aleja lo suficiente de las ideas esencialistas de la matriz heterosexual. Esto se da, según dice, por medio de la idea de identidad que muchas corrientes feministas construyeron como forma de establecer un sujeto político femenino. "En su mayor parte, la teoría feminista ha supuesto que existe cierta identidad, entendida mediante la categoría de 'mujer', que no sólo inicia los intereses y las metas feministas dentro del discurso, sino que constituye al sujeto para el cual se procura la representación política” 
(Butler, 2011, pp. 45-46). En general, las corrientes feministas que Butler criticaba se habían abocado al desarrollo del concepto de identidad como una vía que lograra la igualdad entre hombres y mujeres. En algunos casos y posterior a los años 70, se generó un vuelco hacia la "diferencia sexual"4, en donde se buscaba el mismo fin (reivindicar la identidad femenina), pero por medio de la diferenciación con el hombre. Es decir, existía una identidad-mujer, que se oponía a una identidad-hombre que, al menos hasta ese momento, era la única identidad válida dentro de la sociedad. Para esto, se mantuvo la diferenciación tradicional entre hombre y mujer donde cada una era el opuesta del otro. El problema de esto radicaría en que ambos discursos se ubicarían dentro un marco imperativo de heterosexualidad (que Butler llama heteronormativo), en donde se seguirían perpetuando las categorías excluyentes que se pretendían evadir. Es decir, en la búsqueda de visibilidad y de legitimidad de las mujeres, se mantuvo el discurso binario y representativo del poder heterosexual, y se daba por presupuesta una ontología binaria (hombre-mujer) que se legitimaba no solo por medio de los saberes médicos o legales, sino por el lenguaje en general. Es decir, de alguna manera, muchas corrientes feministas se habían vuelto esencialistas y todas aquellas categorías que no encajaban en estos estrechos límites eran vistos como anormales o raros. El problema que estaba en el fondo era si la constitución de la identidad femenina (en contraposición a la masculina) expresada en la categoría de mujer, ¿era un proceso prediscursivo, precultural o si, por el contrario, esta identidad respondía a un aspecto cultural? Y es aquí donde aparece la distinción entre sexo y género como una exigencia teórica para la construcción de este sujeto político femenino.

La pregunta clásica sobre la relación entre naturaleza y cultura, se tradujo irreflexivamente -según Butler- en la correlación entre sexo y género. Es decir, el sexo es a la naturaleza como el género es a la cultura. El cuerpo sexuado es visto únicamente como un aspecto biológico de los seres humanos, como una característica prediscursiva y precultural, sobre la cual se ciñe el género. Al convertir el género como una interpretación cultural del sexo, se pierde de vista que el género no es un atributo pasivo de la anatomía o

4 Cf. Los trabajos de Julia Kristeva o Luce Irigaray. 
de la biología, ya que esta no es suficiente para brindar las características legitimadoras de las particularidades sociales.

Llevada hasta su límite lógico, la distinción sexo/género muestra una discontinuidad radical entre cuerpos sexuados y géneros culturalmente construidos. Si por el momento presuponemos la estabilidad del sexo binario, no está claro que la construcción de «hombres» dará como resultado únicamente cuerpos masculinos o que las «mujeres» interpreten sólo cuerpos femeninos. ... no hay ningún motivo para creer que también los géneros seguirán siendo sólo dos. (Butler, 2011, p. 54)

La posición de Butler es que el sexo siempre fue al mismo tiempo género y no dos elementos distintos. El sexo es una variable que también se encuentra culturalmente construida. ${ }^{5}$ Por esto, cuando se delimita el sexo como natural, ya se están normalizando y legitimando algunas formas de exclusión y diferenciación. La categoría sexo estaría conformada por interpretaciones de un momento histórico específico con fines legitimadores de un estado de cosas (ser). Ello provoca que el sexo solo tenga sentido dentro una lógica sociocultural, en donde este debe ser binario, estable y, en definitiva, heterosexual. Esto vendría a mostrar que la diferencia sexo-género descansa en una interpretación cultural previa (que tiene como mecanismo legitimador mostrarse como natural), por lo cual, tanto uno como el otro se dan dentro de esta matriz normalizadora y se adaptan a las exigencias epistemológicas y ontológicas de esta misma.

Ahora bien, si tanto el género como el sexo son categorías que surgieron de la misma matriz cultural, ¿cómo podría hablarse de un estrato homogéneo y coherente en la identidad? Y, ¿específicamente de la identidad femenina? Pues bien, puesto que la identidad es resultado de un proceso de significación sociocultural, así como una elección voluntaria que no implica un nexo ontológico con las características biológico-anatómicas, el fundamento debe encontrarse a partir de un análisis crítico del origen

5 Esto no quiere decir que no exista la diferenciación sexual (macho-hembra) o una negación simplista y burda de la morfología humana. Es un planteamiento crítico sobre la relación de las categorías sexo (natural)-genero (construido), que buscar mostrar cómo la relación misma se da desde un punto de vista cultural-social y no desde una lógica "naturalizada". Es decir, como tanto, la categoría "sexo" como "género" solo tienen sentido en una matriz de significación previa. 
de la subjetividad. Inclusive, “... no se puede rastrear el origen del género de forma definible, porque el mismo es una actividad originante" (Butler, en Lamas, 1996, p. 308). Según Butler, si el género no es una categoría que responda a una necesidad ontológica, debe existir algún presupuesto anterior ${ }^{6}$. Este antecedente la autora lo ubica en la llamada metafísica de la sustancia? . De hecho, ella considera que las categorías "hombre" y "mujer" son formas reificadas de esta metafísica sustancial, que se esconden bajo el discurso naturalizado y el lenguaje hegemónico.

El binarismo hombre-mujer (sexo) y su correspondiente género (masculinidad-femineidad) son un producto de una perspectiva que se legitimó a lo largo del tiempo, por medio de prácticas concretas que se vieron reflejadas en el cuerpo y en las manifestaciones sociales de este. Para Butler, el discurso que le dio una realidad ontológica al género es el discurso de la metafísica de sustancia, que crea la apariencia de unidad y homogeneidad en la matriz culturalmente establecida. El sustrato de identidad y unidad que supone ser hombre-masculino o mujer-femenina proviene de los elementos metafísicos del subjectum moderno. Lo que subyace en la idea de identidad de género es lo noción de sujeto, algo idéntico así mismo que se mantiene en el tiempo y que está relacionada con algún tipo de estructura interna (i.e., psicológica). Siendo así, las únicas identidades de género aceptadas o permitidas son aquellas que entren en las reglas de inteligibilidad dadas por la matriz heteronormativa.

Para analizar críticamente esta estructura, se debe partir de una nueva valoración sobre las calidades de lo masculino-femenino u hombre-mujer, por medio de una valoración no sustancial. Lo que, según para la autora estadounidense, es algo que Nietzsche ya había percibido hace tiempo.

El reto que supone reformular las categorías de género fuera de la metafísica de la sustancia deberá considerar la adecuación de la afirmación que hace Nietzsche en La genealogía de la moral en cuanto a que «no hay ningún "ser" detrás del hacer, del actuar, del devenir; "el agente" ha sido ficticiamente añadido al hacer, el hacer es todo». (Butler, 2011, pp. 84-85)

6 No en un sentido histórico-literal, sino de significado.

7 Butler reconoce que la concepción de metafísica de la sustancia se relaciona principalmente con Nietzsche. Cf. El género en disputa (p. 77). 
Nietzsche no tenía presente las grandes implicaciones de esto para el desarrollo de la teoría crítica feminista.

En una aplicación que el mismo Nietzsche no habría previsto ni perdonado, podemos añadir como corolario: no existe una identidad de género detrás de las expresiones de género; esa identidad se construye performativamente por las mismas «expresiones» que, al parecer, son resultado de ésta. (Butler, 2011, pp. 84-85)

La filosofa estadounidense continúa el camino iniciado por Nietzsche y desarrolla la noción de performatividad, con la intención de mostrar que la identidad se forma por un proceso de regulación de las prácticas de género. La "identidad" es un efecto de las prácticas discursivas (performativas) repetidas por los individuos, mantenidas sobre un espacio sociocultural, que se cimienta sobre la supuesta unidad psicológica de un subjectum y que terminan expresándose en el cuerpo. Por lo tanto, el género es temporal y solo se da como un resultado performativo de las múltiples repeticiones de este por los individuos. Los actos constituyen el género y es en la aceptación del género como contraparte social de un aspecto biológico objetivo (sexo) en donde este se presenta como productor de una realidad normativa, puesto que es por medio de la estabilidad e invariabilidad del sexo que se desarrolla la construcción sociocultural del género y a partir de ahí se realizan estas prácticas generadoras de "identidad" hombre-masculino y mujer-femenina.

En otras palabras, actos, gestos y deseo crean el efecto de un núcleo interno o sustancia, pero lo hacen en la superficie del cuerpo, mediante el juego de ausencias significantes que evocan, pero nunca revelan, el principio organizador de la identidad como una causa. (Butler, 2011, p. 266)

Es decir, es solo en la aceptación y repetición de actos (performatividad) que se les confiere sentido a las identidades (i.e., hombre-masculino o mujer-femenina) en cómo se naturalizan las prácticas discursivas heteronormativas y se legitima, subyacentemente, la metafísica de la sustancia. Esta identidad se manifiesta en el cuerpo, ya que es ahí donde el género se muestra principalmente como una impresión cultural, al mismo tiempo que 
se incorpora mentalmente (a nuestro yo) y desde ahí comienza de nuevo, una y otra vez, todo el proceso de repetición.

\subsection{Cadena significante y performatividad}

A partir de estas reflexiones es desde donde el concepto de performatividad butleriana encuentra una intersección con el concepto nietzscheano de subjetividad. Según lo hemos venido señalando, para Butler el sujeto culturalmente constituido es participe en conservar, mantener modos de comportamiento y repetir estereotipos de identidad de género a través de iteraciones constantes de características físicas, verbales y psicológicas. De esta manera, el género solo existe en la medida en que estamos dispuestos a creer que así es. Decir que el género es performativo implica que está culturalmente escrito y que se naturaliza en la mayoría de los sujetos a través de la internalización psicológica y la repetición. Sin embargo, dentro de esta matriz se presenta la posibilidad de que las identidades puedan ser reinterpretadas a partir de perspectivas particulares (i.e., identidades queer) que se organizan desde manifestaciones individuales de corporalidad o de comportamiento. Esto implica que las identidades se pueden organizar de nuevo, lo cual es, sin duda, coherente con las "fuerzas activas" y con la "pluralidad de voluntades de poder" de las que habla Nietzsche.

Esto, además, está metodológicamente ligado a idea de genealogía nietzscheana, ya que esta pretende mostrar el origen de la voluntad de poder dominante, permitiendo al mismo tiempo mostrarla como histórica, lo que implicaría la posibilidad de la divergencia y el cambio. Para Nietzsche las diferentes matrices de poder se imprimen en el cuerpo y se manifiestan en él. Aun a pesar de que no son una manifestación total e inamovible de ellas, puesto que la corporalidad nunca es un mero reflejo de las fuerzas o de la colectividad de almas que representa, sino que es algo propio del individuo. Para el filósofo alemán, esto implica siempre una respuesta ante las demandas que se han establecido en la colectividad. Esta idea resulta muy importante para la TQ, ya que permite la creación de nuevas identidades no esencializadas o naturalizadas. De hecho, la misma Butler le reconoce esta idea a Nietzsche: 
En cierto modo, para Foucault, igual que para Nietzsche, los valores culturales aparecen como consecuencia de una inscripción en el cuerpo, entendido como un medio, ... no obstante, para que esta inscripción pueda significar, ese medio en sí debe ser destruido, es decir, debe ser completamente transvalorado... (Butler, 2011, pp. 256-257)

A pesar de que también se menciona a Foucault, el lenguaje utilizado es de cuña nietzscheana. En la "genealogía crítica" de Butler, las reiteraciones constantes de las normas de género internalizadas pueden reinterpretarse (lo cual nos recuerda el perspectivismo) para reinventar o modificar constantemente lo que se entiende por género, creando espacios de significado para las identidades queer. Aun cuando no toma en cuenta las "fuerzas corporales activas" que menciona Nietzsche, está plenamente de acuerdo con él en su enfoque antiesencialista y perspectivista, sobre todo en el origen cambiante de la inteligibilidad cultural (voluntad de poder dominante en Nietzsche o la matriz heteronormativa en Butler). La performatividad es una forma específica del poder ${ }^{8}$. Es una manifestación de la matriz de poder hegemónico.

De igual manera, si atendemos las implicaciones de las interpretaciones nietzscheanas para la TQ, se podría evitar caer en una lectura errónea de los actos performativos, que tiene cierta difusión. Desde una lectura voluntarista de la subjetividad en Butler, se menciona que el individuo puede adoptar libremente, sin ninguna restricción social, nuevas interpretaciones de su género. Llegando, incluso, a cambiarlo de un día para otro si así lo desea (algo parecido al relativismo que también se le endosa a Nietzsche). Sobre este punto, baste decir que Butler ya ha negado y aclarado esto en repetidas ocasiones. Sin embargo, valga esto para traer a colación, de nuevo, que la dimensión nietzscheana de la posición de Butler aquí aclara el error de esta interpretación, ya que Butler sostiene la idea (ya hace tiempo desarrollada por Nietzsche) de que el poder articula, por medio de una serie de cadenas complejas, cuáles interpretaciones se consideran válidas o no. La perfomatividad es "... una modalidad específica del poder, entendido como discurso. Para poder materializar una serie de efectos, el discurso debe entenderse

8 Butler desarrolla esta idea con más detalle en Cuerpos que importan. 
como un conjunto de cadenas ${ }^{9}$ complejas y convergentes cuyos 'efectos' son vectores de poder" (Butler, 2005, p. 267).

Butler no toma de manera literal las ideas de Nietzsche, pero mantiene el sentido original de ellas, en tanto acepta el origen genealógico de la identidad. No obstante, lo que esto sí muestra con mayor claridad es la importancia de Nietzsche para un estudio critico que busca repensar la identidad de género, en vista de que las críticas que él realiza a la metafísica de la sustancia abren todo un espacio de posibilidades para el desarrollo performativo de la identidad.

Tanto Nietzsche como Butler cuestionan el lenguaje que produce la internalización de las identidades estereotípicas, lo que para la TQ es relevante, puesto que implica que el cuerpo (sexo), producto de los actos performativos, no tiene un estatus ontológico más allá de los actos iterativos que constituyen su realidad social.

Si esto, además, lo relacionamos con la idea de la identidad femenina, es evidente que implica un rechazo frente al esencialismo femenino, tal y como lo hace Nietzsche ${ }^{10}$, solo que, a diferencia de él, Butler considera la formación discursiva del género como producto de la matriz heteronormativa, a que a su vez es deudora del discurso de la metafísica de la sustancia.

La filosofa feminista, siguiendo el método genealógico, cree que la "mujer" tiene una historia y una identidad mutable que es producto de una multiplicidad de perspectivas, por lo que cada mujer realizaría su género, de acuerdo con su propia interpretación. Esto le permitiría definirse aún dentro del concepto "mujer", debido a que comprende que la noción de identidad gira en torno a prácticas concretas. Es decir, siendo coherente con la idea de la performatividad, cada una de las repeticiones performativas forma parte de una cadena significante (genealógica), en la medida de sus relaciones con el discurso de poder; lo que es muy parecido al perspectivismo nietzscheano, ya que está formada por aspectos culturales, así como por las confluencias de las voluntades, deseos e interpretaciones personales.

La posición antiesencialista de Butler en cuanto a las identidades de género representa una derivación coherente de la postura nietzscheana,

9 Estas cadenas complejas, son la versión butleriana de lo que Nietzsche nombró como "cadena de signos" (Nietzsche, Genealogía de la moral. § 12)

10 Cf. Piedra. Nietsche y las mujeres. A propósito de su misoginia. 
así como de su genealogía, pues para ambos no existe un sujeto metafísico preconstituido o preexistente a la dinámica social en el cual se muestra. Inclusive, podemos encontrar muchas similitudes entre ambas interpretaciones. La idea nietzscheana de que no hay un sujeto objetivo, la TQ la reformula y sostiene que no hay un género objetivo que responda a un sexo igualmente objetivo, lo cual es muy importante para el desarrollo de las nuevas identidades de género. El rechazo de Nietzsche a las "verdades objetivas" o a la "razón pura" reconoce la naturaleza cambiante y fluida de la vida (o en este caso del conocimiento), al mismo tiempo que no desvaloriza la importancia de las definiciones subjetivas que se basan en la interpretación personal, permiten, por ejemplo, que nuevas identidades de género sean validadas a través de la existencia y el tiempo, al mismo tiempo que sirve para exponer y explicar la lógica de la matriz heteronormativa. Esta lectura de Nietzsche es muy enriquecedora porque muestra que no hay un modo verdadero de asumir el género, porque no existe un modo correcto o natural del género (no hay verdades objetivas). No hay ningún vínculo ontológico (más que el que la matriz de poder desea mantener) entre el género y los cuerpos sexuados. Por medio de la destrucción metafísica que realiza Nietzsche al subjectum se puede reconocer que incluso las categorías "biológicamente" dadas son constructos fueron producidas por eventos históricamente o políticamente importantes. Como la "voluntad de poder" siempre quiere perpetuarse y acrecentar su poder, estas categorías naturalizadas se reproducen una vez que un grupo social se reconoce como tal, por medio de los mismos miembros que los componen, ya que la determinación de algo como "biológico" o "natural" se da como un presupuesto mismo para la conformación de estos grupos o identidades de grupo.

Esto nos indica que, al menos, en este aspecto, Nietzsche y Butler están muy cerca en términos o perspectivas sobre las expresiones de la identidad individual. Esto se debe a que sus dos filosofías tienen, como base, el punto de que hay una falta de verdad inherente acerca de la identidad y, por lo tanto, la identidad solamente se forma mediante la acción. Aquí podemos ver que la manera en que se amplía la inteligibilidad cultural; según las prácticas performativas divergentes, encuentra gran similitud en la forma en que la teoría nietzscheana explica el conocimiento a través de una interacción con otras perspectivas. Los "muchos ojos" que el alemán 
mencionaba que eran necesarios para tener una mejor comprensión de la realidad se vuelven claves para la TQ; ya que es solo en el encuentro con las identidades divergentes (o extrañas) como se empezarían a dar estos ciertos actos (que Butler mencionaba) que puedan tener efectos sobre la base discursiva de la matriz heteronormativa. Es solo por medio de la experiencia con las otras perspectivas sobre el género y su identidad subjetiva, como se puede aumentar comprensión de este concepto. Es precisamente esto, lo que a la postre le permite, a la autora estadounidense, plantear la posibilidad de crear nuevas significaciones que no se ajusten a la lógica binaria, haciendo posibles espacios que se escapen a los esquemas cognoscitivos o corporales heteronormativos.

\section{Conclusión}

Nietzsche nunca hizo una referencia a la identidad de género, aun cuando en sus textos hay constantes referencias a la mujer o la femineidad e inclusive la "objetividad de la identidad", por ejemplo. Es evidente que el contexto del alemán era muy diferente al actual, sin embargo, si partimos del reconocimiento del patriarcado y el androcentrismo, nada impide interpretar a Nietzsche desde la TQ, algo que, de hecho, Butler realizó. Nuestra posición al respecto es que las herramientas que aparecen en la literatura nietzscheana resultan de mucha ayuda para la comprensión de las relaciones de poder, desde la óptica de reproducción y, en otras ocasiones, desde los cambios que se presentan en las fuerzas activas que las componen. Sin duda alguna, la deconstrucción que realizó de la metafísica de la sustancia es fundamental para analizar la identidad de género y problematizar su obra desde esta perspectiva.

El mero hecho de que Nietzsche siempre recalcó, por medio de su genealogía, las totalizaciones epistemológicas y las pretensiones dogmáticas de ciertas teorías, muestra su utilidad para el análisis social de construcciones naturalizadas como "hombre" o "mujer". La heterogeneidad y apertura de su pensamiento es ya un marco que permite mostrar, en su vertiente sociocultural, las prácticas discursivas que regulan el comportamiento y la expresión de la sexualidad en los cuerpos.

Esto es, desde luego, una de las principales pretensiones de la TQ. 
Un NieTzSCHE EXTRAÑo: INTERSECCIONES ENTRE El PENSAMIENTO NIETZSCHEANO Y LA TEORÍA QUEER A Queer Nietzsche: Intersections between Nietzschean thought and Queer Theory

\section{Referencias}

Butler, J. (2001). Mecanismos psíquicos del poder. Ediciones Catedra. Universitat de Valencia. Butler, J. (2005). Cuerpos que importan. Sobre los límites materiales y discursivos del "sexo". Buenos Aires: Paidós.

Butler, J. (2011). El género en disputa. Madrid: Espasa Libros.

Duque, C. (Enero-junio, 2010). Judith Butler: Performatividad de género y política democrática radical. La Manzana de la Discordia, 5(1), 29.

Foucault, M. (2006). Historia de la sexualidad I. La voluntad de saber. Madrid: Siglo XXI Editores.

Lamas, M. (1996). El género: La construcción cultural de la diferencia sexual. México: Porrúa.

Nietzsche, F. (1985a). Así habló Zaratustra. Madrid: Alianza Editorial.

Nietzsche, F. (1985b). Más allá del bien y del mal. Madrid: Editorial EDAF.

Nietzsche, F. (1988). Sobre la verdad y mentira en sentido extramoral. En J. B. Llinares Chover (Ed.), Nietzsche, antología. Madrid: Ediciones Península.

Nietzsche, F. (1996a). El nacimiento de la tragedia (Trad. A. Sánchez Pascual). Madrid: Alianza Editorial.

Nietzsche, F. (1996b). Humano demasiado humano. . Madrid: Ediciones AKAL.

Nietzsche, F. (2001). La ciencia jovial. Madrid: Biblioteca Nueva.

Nietzsche, F. (2003a). El ocaso de los ídolos (2 ed.) Barcelona: Tusquets Editores.

Nietzsche, F. (2003b). Genealogía de la moral ( $2^{\circ}$ ed.). Madrid: MESTAS Ediciones.

Nietzsche, F. (2006). El nihilismo europeo. Fragmentos póstumos (otoño, 1887). Madrid: Biblioteca Nueva.

Nietzsche, F. (2010a). Fragmentos póstumos (Vo. I, 1869-1874, Trad. Luis de Santiago Guervós, 2da ed.). Madrid: Tecnos.

Nietzsche, F. (2008a) Fragmentos póstumos (Vol. II, 1875-1882, Trad. Manuel Barrios y Jamie Aispunza). Madrid: Tecnos.

Nietzsche, F. (2010b). Fragmentos póstumos (Vol. III, 1882-1885, Trad. Diego Sánchez y Jesús Conill. Madrid: Tecnos.

Nietzsche, F. (2008b) Fragmentos póstumos. Vol. IV, 1885-1889, Trad. Juan Luis Vermal y Joan B Llinares, $2^{\text {da }}$ ed.). Madrid: Tecnos.

Schacht, R. (2015). Nietzsche. New York: Routledge. 